\title{
Multimodal Virtual Environments: an opportunity to improve Fire Safety Training?
}

Fires and fire-related fatalities remain a tragic and frequent occurrence. Evidence has shown that humans adopt sub-optimal behaviours during fire incidents and, therefore, training is one possible means to improve occupant survival rates.

We present the potential benefits of using Virtual Environment Training (VET) for fire evacuation. These include experiential and active learning, the ability to interact with contexts which would be dangerous to experience in real life, the ability to customise training and scenarios to the learner, and analytics on learner performance. While several studies have investigated fire safety in VET, generally with positive outcomes, challenges related to cybersickness, interaction and content creation remain. Moreover, issues such as lack of behavioural realism have been attributed to the lack realistic sensory feedback. We argue for multimodal (visual, audio, olfactory, heat) virtual fire safety training to address limitations with existing simulators, and ultimately improve the outcomes of fire incidents.

Keywords: fire safety; multimodal virtual environments; virtual reality; OSH; simulation; training

\section{Introduction}

In 2018 Fire and Rescue services in England reported attending 167,150 fires and over 300 fire related fatalities, including 71 associated with the high-profile Grenfell tower incident (Home Office National statistics, 2018). Unsurprisingly, the implementation and monitoring of safety regulations and the interest in fire safety systems and equipment are increasing (MarketWatch, 2018). Research on Human Behaviour in Fire (HBiF) during real-world fire incidents has suggested that a lack of knowledge relating to the spread and movement of fire often means that occupants are unprepared and misjudge appropriate actions (Wood, 1980; Chittaro \& Ranon, 2009). Effective training in fire safety behaviours is therefore a means to improve occupant survival rates by reducing evacuation times and potentially fatal errors (Chittaro \& Ranon, 2009; Kinateder et al., 2014; Kobes, Helsloot, de Vries, \& Post, 2010a).

Despite the potential benefits of fire safety training, traditional training methods often fail to motivate and engage target audiences (Chittaro \& Buttussi, 2015). For example, the use of pre-planned, emergency evacuation fire-drills can prove disruptive to the workforce and costly to the employer and are not typically organised to address the training needs individuals require for particular tasks, limiting their educational value. Additionally, fire drill simulations typically lack critical psychological and affective elements associated with a fire emergency, for example smoke-filled corridors, resulting in unrealistic behavioural responses such as a lack of urgency (Chittaro \& Ranon, 2009; Gwynne et al., 2017; Smith \& Trenholme, 2009).

One possible solution is Virtual Environments (VEs), which can provide value in education and training, and particularly afford learning in contexts where experiential learning is not normally possible for safety reasons (Crosier, Cobb \& Wilson, 2002; Dalgarno \& Lee, 2010). VEs can take different forms, although many people commonly 
associate Virtual Reality with Head-Mounted Displays (HMDs), an example of which is shown in Figure 1. With HMDs, the eyes view the same virtual scene, but the images are displaced, giving binocular vision and thus the effect of depth and three-

dimensionality (Wann, Rushton \& Mon-Williams, 1995). However, VEs can also be viewed through other display technologies, such as screens or projectors viewed with 3D glasses, or on standard PC monitors or laptop screens without the $3 \mathrm{D}$ effects (Figure 2). VE-based education can be used to ensure competence before exposure to the real environment; "expose" workers to high-risk scenarios in a safe and controlled simulated environment; help workers understand the causes and consequences of incidents through virtual recreations with a view to preventing future incidents; help workers understand the importance of procedural changes; and identify hazards through the afforded ability to assimilate and integrate salient information (McMahan, Schafrik, Bowman, \& Karmis, 2010; Nickel, Pröger, Lungfiel, \& Kergel, 2015; WebberYungman \& van Wyk, 2013).

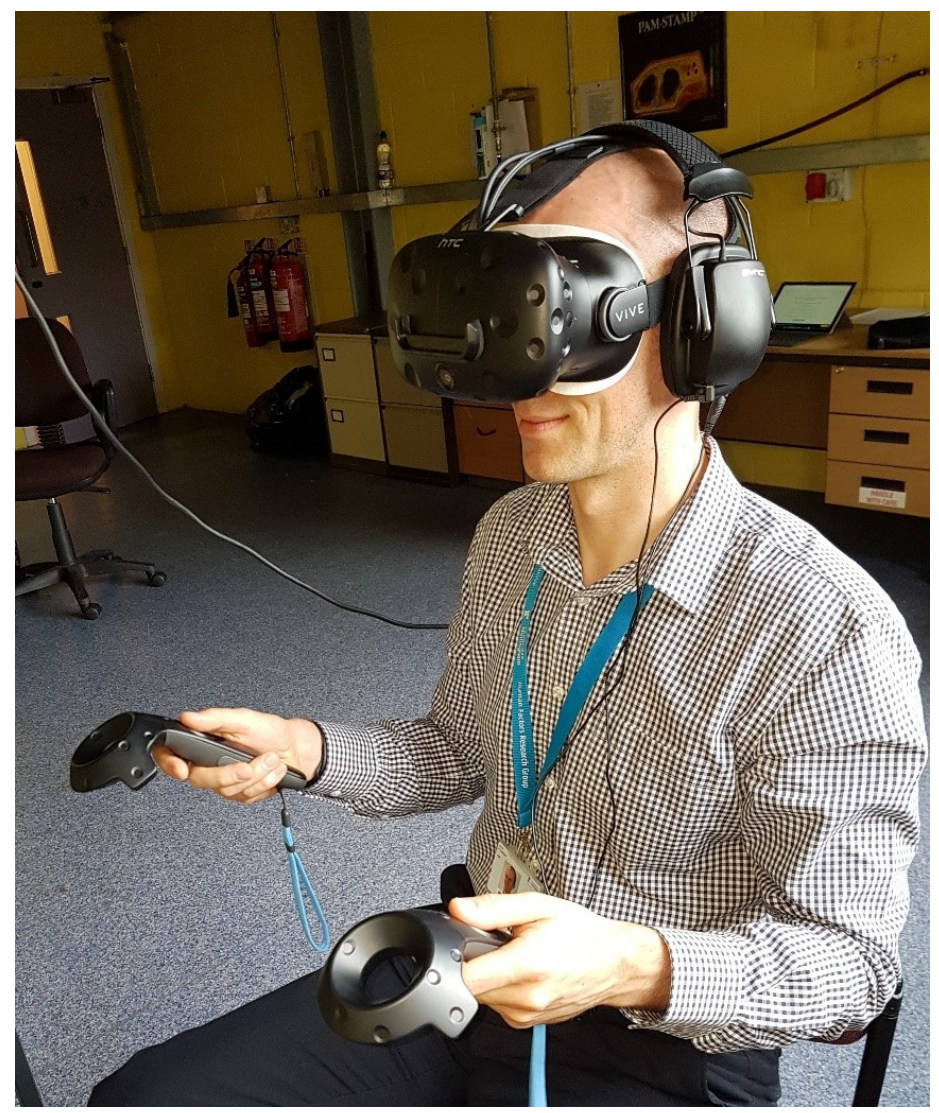

Figure 1. Head-Mounted Display (HMD) 


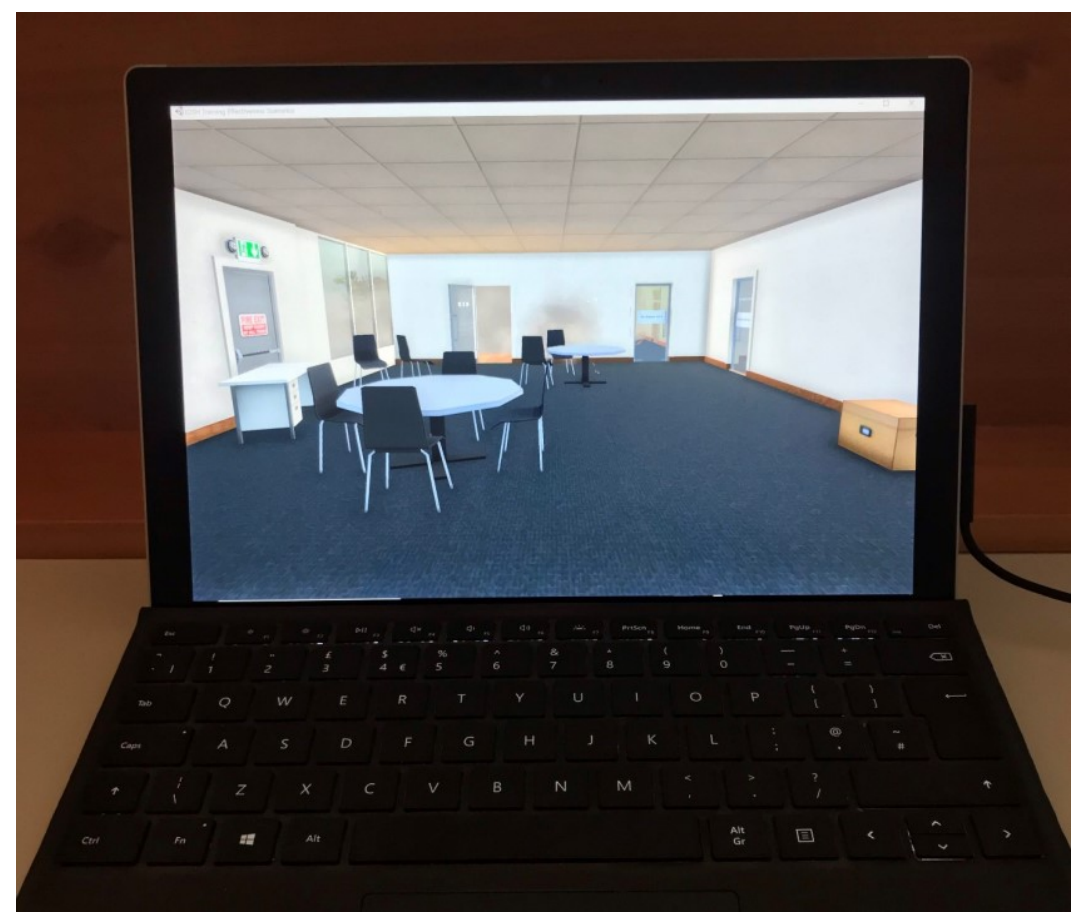

Figure 2. VE displayed on a standard computer display screen

However, further work is needed to develop VEs and prove their effectiveness for OSH and fire safety training in particular. For example, Smith and Trenholme (2009) found that participants using a virtual fire drill environment demonstrated unsafe behaviours such as opening doors with smoke coming from underneath them, attributed to a lack of heat in their simulation. Multisensory simulation has been seen to improve performance when training with VEs (Jiang, Girotra, Cutkosky, \& Ullrich, 2005) but this has never been tested in fire evacuation training. Indication of heat (at a safe temperature) during a simulated emergency is technically possible, and may increase the validity of the experience and therefore increase its effectiveness in fire safety training. Similarly, little previous work has investigated the role of olfactory cues in Health and Safety training despite its obvious importance as a cue for building occupants to recognise the presence of a fire and other applications e.g. identification of a dangerous chemical. Smell simulation technology is now penetrating the consumer market, with an associated reduction in cost, and offers the potential for a virtual experience which is perceptually equivalent to the target scenario (Chalmers \& Ferko, 2008). Thus, it is timely to investigate the usefulness of olfactory simulation in understanding employees' behaviour and training for OSH activities.

Virtual Environments (VEs) offer potential benefits to fire safety training by: (a) increasing trainees' engagement and understanding by allowing them to explore and experience the consequences of their actions in safety-related scenarios, thus improving compliance with OSH training; (b) customising the environments to trainees' own workplaces to improve relevance of the training and to facilitate context-dependent learning; (c) reducing costs by allowing trainees to train at their local areas and at their convenience rather than travelling to dedicated training facilities; and (d) more accurately representing a real emergency. This paper presents an argument for using Virtual Environments in Fire Safety Training and describes the rationale behind the development of a multimodal (vision, auditory, thermal, smell) VE for fire safety training, based on the evidence available from the academic literature. We also propose the use of low-cost off-the-shelf technologies to maximise uptake and explore the 
notion that the VE can be customised to individual company premises. Considerations for design and implementation of a low-cost system are presented.

\section{The advantages of Virtual Environment Training (VET)}

Virtual Environment Training (VET) has already been successfully employed in fields such as medicine, military, architecture, flying and others (Perez, Marin, \& Perez, 2007). VET offers several advantages over conventional training and other technologybased training, as outlined below:

Experiential and active learning. VET can provide experience-based learning that enables trainees to observe the consequences of their actions (Bandura, 2001). Moreover, learning in VE in an interactive way encourages users to actively participate in the experience and provides 'first-hand' experience rather than the vicarious, 'second-hand' experiences provided by other forms of learning, such as classroom lectures, manuals and videos (Winn, 1993). An example in fire safety training is shown in Figure 3. According to McGuire (1996), this active learning process helps the learner to achieve understanding of the real world via an "ongoing process" that produces a sense of new information through their own version of reality, compared to the conventional training which is based on the trainer's perspective. Trainees in VET absorb knowledge in a free-way, for example moving and interacting autonomously and engaging in self-directed activities among their learning contexts, or experiencing the consequences of their actions (Leder, Horlitz, Puschmann, Wittstock, \& Schütz, 2019). As a result, this can lead to greater effectiveness of the training (Mantovani, Castelnuovo, Gaggioli, \& Riva, 2003).

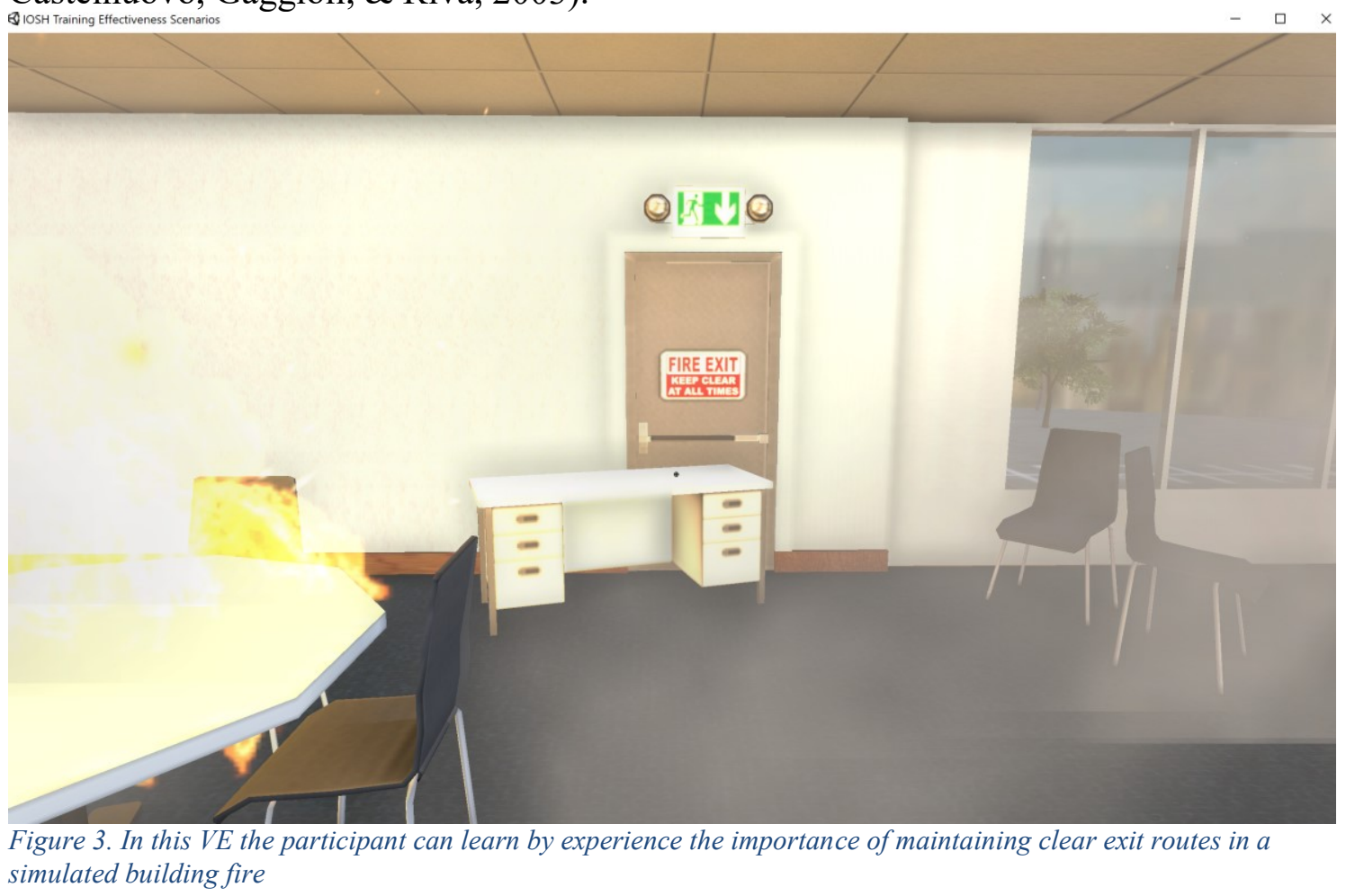

Visualisation and reification. VE systems enable the users to perceive and interact with information and/or objects in ways which are impossible with other media. For example, videos and computer animation can provide outstanding and realistic animations and graphical representations, but these scenes are fixed sequences of 
images, predetermined by someone else and do not afford any interaction to the users (Kalawsky, 1996; Laurillard, 2010; Travis, Watson, \& Atyeo, 1994). By contrast, VEs allow the users to enter a virtual world where they are able to perceive the surroundings from distinct perspectives; at the same time, they can move through the environment or control objects in the virtual world. These kinds of interaction generate a clear relationship between the objects, the environment and the event (Perez et al., 2007). Subsequently, researchers have stated that VEs offer a spatial perception and continuous visual feedback improving the development of spatial models in terms of learning in training from the user's perspective, which can be used in real life situations (Winn, 1993; Witmer, Bailey, Knerr, \& Parsons, 1996). Thus, interacting with the real environment after interaction in a VE may be superior over non-interactive media for transfer of training.

Training in contexts impossible or difficult to experience in real life. VEs are capable of offering interaction, observation, examination and some other experiences that are impractical or impossible to achieve via other means (Dalgarno \& Lee, 2010; Mantovani et al., 2003). For example, Freeman et al. (2001) implemented a VR patient simulation system in order to teach critical emergency response skills to medical providers in the U.S. for events which are rare in the real world. Their VR system had the capability of providing an experimental, problem-based training method which engaged the trainees in a stressful, high-fidelity world as well as offering multiple learning chances among a shortened period of time than would occur in the real world. A firefighter training simulator reported in Cha, Han, Lee, \& Choi (2012) is another example. Safe, convenient, and repetitive training was provided to firefighters of a vehicle fire in the Jukryeong Tunnel in Korea; this would rarely be possible in an actual tunnel (Cha et al., 2012).

Motivation enhancement. Interaction in a VE can be motivating and engaging, particularly when the VE is personalised and individuals seek to achieve their goals within them (Dalgarno \& Lee, 2010). This can be further enhanced by using a game format to make the learning more interesting and fun (Mantovani \& Castelnuovo, 2003). Game-based systems often use elements such as exploration, challenge and progression through levels. While often enjoyable to interact with, such systems have a purpose (in this case learning about fire safety), hence they are often referred to as "serious games".

Adaptability and flexibility. VEs can be tailored according to the characteristics and needs of the trainees. For instance, VEs can enable learners to process training and manipulate objects according to their experience and competence, at their own pace, and at a time that suits them. Moreover, it is possible to create and conduct training in a VE which represents trainees' own physical locality (Mantovani, 2003; Smith \& Veitch, 2019). This has the potential to improve training by increasing its relevance to an evacuee's own location. Moreover, it presents the possibility to train geo-specific aspects such as the location of fire safety elements, or the layout of buildings and evacuation routes.

Scenario design. The ability to design scenarios is a key element in realising the benefits of VET. VEs enable developers to create scenarios in order to fulfil distinct training purposes. A scenario illustrates a hypothetical, but plausible, circumstance that may be employed for a variety of purposes. Although it may not decrease uncertainties corresponding to a future case in the real world, the scenario can generate a more concrete situation; as a result, users are able to practise proposed response strategies or crisis management systems in a self-consistent and reasonable manner (Luo, Yin, Cai, Lees, \& Zhou, 2013). Furthermore, multiple varying scenarios can be used to explore 
different hypothetical scenarios. For example, trainees can be exposed to a fire in which different exit routes are blocked, in which different flammable materials are present, or where they are in different parts of the workplace, and can experience the differences in each. This is typically not accommodated by structured training and drills.

Evaluation and assessment. Due to their reliance on computational technology, VEs provide good opportunity for measuring learning and performance as the sessions can be easily monitored and recorded (Taffinder, 1998). Moreover, they provide the opportunity to implement other features in support of training, such as reviewing the training experience from a different perspective (e.g. birdseye view to help understand evacuation route choice), or in real-time, sped up or slowed down, or fast-forwarded to key decision points to review with a trainer.

\subsection{Challenges and considerations with virtual training environments}

While VEs offer the potential advantages outlined above, there are challenges associated with VET. Some of the main challenges are outlined below:

Sickness issues. Several studies have reported that use of VEs can bring about symptoms of simulator sickness (e.g. Nichols, Cobb, \& Wilson, 1997; Ragan, Bowman, Kopper, Stinson, Scerbo, \& McMahan, 2015; Sharples, Cobb, Moody, \& Wilson, 2008). The sickness is associated with a wide range of symptoms, including: headache, eyestrain, dizziness, fatigue and nausea (Sharples et al. 2008). Research from car simulators has shown that users adapt their behaviour while experiencing sickness (Burnett, Irune, \& Mowforth, 2007; Nichols, 2000; Sharples, Burnett and Cobb, 2011), which indicates that this phenomenon can fundamentally alter the usefulness of the VE. There are differences in the level of sickness symptoms attributed to VR display type, with Head-Mounted Display (HMD) often causing more (e.g. Sharples et al., 2008). With regards to the reasons behind HMD sickness, some scholars (e.g. DiZio \& Lackner, 1997; Jennings, Reid, Craig, \& Kruk, 2004) attribute it to lag in the display which leads to sensory conflict; these temporal delays are caused by update rates and processing times which start from the user input (e.g., head movement, in the case of a HMD, or joystick controlled movement) to the corresponding system's output (e.g. visual consequence on the scene displayed (Rebelo, Noriega, Duarte, \& Soares, 2012)). Importantly, Jensen and Konradsen (2018) report that cybersickness negatively impacts attitudes towards virtual training technologies, and is associated with poorer learning.

Proven effectiveness of the training. VEs, like other instructional training technologies, must consider evidence for the effectiveness of the training (Winn, 1993), which has seen mixed results in the academic literature. The success of the VET depends on the nature of the training and on the instructional content, and on whether the environments grant engagement and stimulate elements such as reasoning skills, transfer of knowledge and other factors that support training (Perez et al., 2007). While there is some evidence for the effectiveness of VR-based training in different domains such as automotive/manufacturing (Borsci, Lawson, \& Broome, 2015; Langley et al., 2016; González-Franco et al., 2017; Gavish, Gutierrez Seco, Webel, Rodriguez, Peveri, \& Bockholt, 2011; Gavish et al., 2015; Webel, Bockholt, Engelke, Gavish, Olbrich, \& Preusche, 2013), aviation (Buttussi \& Chittaro, 2018) and medical (Pfandler, Lazarovici, Stefan, Wucherer, \& Weigl, 2017; Youn, 2007; Youngblood, Srivastava, Curet, Heinrichs, Dev, \& Wren, 2005), there are often methodological concerns with the research. These include a focus on a limited set of performance criteria, often time and error (Borsci et al., 2015), lack of validation of the evaluation methods and a tendency 
towards user evaluations (rather than controlled studies of training effectiveness) with positive results bias (Jensen \& Konradsen, 2018). There is also a lack of research on higher level cognitive skills, with most research focussed on remembering or understanding facts (Jensen \& Konradsen, 2018).

Interaction and control issues. There are several issues with controlling movement in a virtual environment which arise as a consequence of the interface layer between the user and the virtual world. Input devices, such as a standard mouse, joysticks or other controllers, do not afford similar feedback to that received in the real world and, consequently, users can have difficulty navigating in VEs (Witmer et al., 1996). Lawson (2011) found users demonstrated overshoot errors, difficulties getting through doors, and frequently got lost when navigating a fire evacuation in a VE. Smith and Trenholme (2009) report longer evacuation times in a virtual building evacuation than in the real world, attributed to control issues. In addition to the control interface, distance estimation may affect interaction with the VE, as users consistently underestimate distances in virtual environments, attributed to the difficulties in measuring perception of distance, the construction of the virtual environment, the technology used and human factors issues (Renner, Velichkovsky, \& Helmert, 2018). Moreover, the field of view in a VE is usually less than the natural human field of view (Jensen \& Konradsen, 2018; Riva, Wiederhold, \& Gaggioli, 2016) which can result in differences in how the user perceives navigation cues between the real and virtual worlds.

Content creation. While the costs of VR equipment have reduced considerably in recent years (Jensen \& Konradsen, 2018), there is still a resource associated with buying and developing VETs. Smith and Trenholme (2009) report that their virtual replica of a multi-storey computer science department took a single developer three weeks to construct. It could take considerably longer for someone without VE development experience. Notably, the creation of the environment is in addition to the instructional design required to create effective training content.

\subsection{Existing studies of VR in Fire Safety Training.}

Several studies have already investigated VR in fire safety training, or in the study of human behaviour in fire scenarios. These have shown performance improvements which have been attributed to the VET. For example, Tate, Sibert, and King (1997) evaluated the effects of employing VE to train shipboard fire fighters in the navy in comparison with conventional methods of mission preparation. Navy trainees wore an HMD and used 3D joysticks to interact with the VE. Despite a limited sample size, the study demonstrated that VE-trained participants completed a navigation mission faster, and committed fewer mistakes (navigational errors), than a control group who had been trained using traditional approaches (Tate et al., 1997).

More recent evidence is provided for the training benefits of virtual environments by Smith and Veitch (2019) who compared simulation-based training to lecture-based training in four offshore emergency response procedures. They used a mastery-based approach with their VET, in which competence needed to be achieved before progressing to the next task. Reported outcomes were; task performance improvements, less time required for the training, and more risk-averse behaviour (Smith and Veitch, 2019). They conclude that simulation-based approaches are not only useful in demonstrating competence, but can also help address individual variability by customising the training to learner needs. 
Some researchers have focussed on the validity of behaviours that users demonstrate in VEs, with some explicitly mentioning the importance of this as an indicator of their utility in training (Gamberini, Cottone, Spagnolli, Varotto, \& Mantovani, 2003). Gamberini et al. (2003) investigated participants' responses to a fire emergency in a virtual library. The participants wore an HMD and used a joystick to interact with the VE. Initially, participants were given the chance to navigate without any hazardous phenomenon so that they could orient themselves within the VE. They were then required to arrive at a predetermined point in which an emergency would be initiated. The researchers found that the participants identified the emergency and responded with behavioural adaptations, such as movement patterns more focussed on evacuation, and concluded that the VE is suitable both for studying behaviour in emergencies, and as a training tool. Kobes et al. (2010a) compared evacuation behaviour in a real hotel to a virtual one, and concluded that generally wayfinding behaviour demonstrated relative validity, with the exception of a scenario in which exit signs were located near the floor; in this condition participants in the virtual environment demonstrated an unexpected tendency to not use the nearest exit route. In a related study which also used a virtual hotel, Kobes, Helsloot, de Vries, \& Post (2010b) reported the influence of smoke on evacuation behaviour, which increased the likelihood of evacuees using a closer exit. Virtual Environments have also been used to study evacuation signage (Duarte, Rebelo, Teles, \& Wogalter, 2014; Tang, Wu, \& Lin, 2009). Duarte et al. (2014) argue for the validity of their results based on a comparison to previous events in the real world. They also highlight the usefulness of VE as a research tool, given the need to avoid exposing study participants to hazards. However, Tang et al. (2009) express concern that some of their results, in particular that construction and fire safety workers were not significantly better at wayfinding than the general population, may not be replicated in the real world. However, this concern is not rationalised, so would require further investigation.

Another area of focus in the prior literature has been on enhancing the realism of fire and smoke simulation in virtual environments, often using computation fluid dynamics (CFD) (Cha, Han, Lee, \& Choi, 2012; Ren, Chen, Shi, \& Zou, 2006; Ren, Chen, \& Luo, 2008; Smith \& Erickson 2009). Ren et al. (2006; 2008) developed a simulation of a subway, using CFD, which they propose as a safe and inexpensive tool for virtual fire drills and training. However, their focus is on the technical development and do not present any behavioural outcomes or user tests. Cha et al. (2012) developed a VET simulator providing a wide range of experiences for the general public or inexperienced trainers and commanders so that they were able to make quick decisions, and safe and organized responses in real-world situations. They believed that CFD could improve the fire and smoke graphics. User feedback from firefighters was positive on the realism of the fire in their simulation, and they commented that the VET had potential for training applications, although this was not tested empirically. Their feedback also included a request for gamification elements and a diverse range of scenarios to reflect the variability of events in real life. The users also requested multisensory feedback such as touch and heat, given the importance of non-visual cues to firefighters for example when finding their way in the dark and through smoke-filled environments by relying on tactile perception through hands (Cha et al., 2012).

The gamification topic has been raised by other authors, in recognition of its contribution to improving training experiences or outcomes (Backlund, Engstrom, Hammar, Johannesson, and Lebram, 2007; Backlund et al., 2009; Chittaro \& Ranon, 2009; Ribeiro, Almeida, Rossetti, Coelho, \& Coelho, 2012; Smith \& Trenholme, 2009). The potential advantages of game-based evacuation training include greater motivation 
for building occupants to engage with the training material (which is more interesting than traditional training material) and therefore spending longer engaging with it, and the ability to customise the training according to the users' training needs (Chittaro \& Ranon, 2009; Ribeiro, Almeida, Rossetti, Coelho, \& Coelho, 2012). Chittaro and Ranon (2009) also recognise the potential importance of VET to employers, in that it may have less of an impact on company processes than traditional training approaches, and would be safe for trainees. User feedback on a game-based system included a desire to understand more about the effects of heat on their character, and a need to increase the emotional intensity of the game-based training. Chittaro and Ranon (2009) emphasise the importance of studying retention and transfer of the training knowledge to the real world in future work. Smith and Trenholme (2009) used a gaming-platform to develop their fire evacuation simulation, in recognition of the time advantages such technologies bring to creating a bespoke VE. While they found the patterns of evacuation times for their three scenarios were consistent between the real world and the VE, the overall times differed. This was also affected by gaming experience, as also seen by Riberiro et al. (2012) who found virtual evacuation times were quicker for regular video game players. Smith and Trenholme (2009) report on behaviours seen in the VE which they would not expect in real life, such as going through a door with smoking coming from underneath it, and attribute this behavioural discrepancy to the lack of multimodality in their simulation. They also report on the lack of interactivity with some salient objects such as fire extinguishers. Backlund et al. (2009) provided some interactivity with salient object by including physical artefacts (a hoze nozzle and breathing mask) within a CAVE virtual environment. They present an architecture for a game-based simulator, using game-based features such as progression through levels with different learning objectives. The outcomes of the user testing was that generally an appropriate level of fidelity was achieved. Similar to the findings from Chittaro and Ranon (2009), they report on the importance of psychological strain on the training experience, and propose the simulator as a useful tool to prepare students for live training, by progressing them along the learning curve before the real training (Backlund et al., 2009). In an earlier study of their simulator, Backlund et al. (2007) demonstrate learning effects, as participants performed better in the simulator on subsequent uses. They also report high levels of user-enjoyment, attributed to the game-based approach, but also note instances of cybersickness.

\section{Proposal for a multisensory virtual environment training simulator}

It is apparent that Virtual Environment Training can offer a number of positive outcomes in emergency preparedness. However, previously systems have focussed predominantly on visual simulation and these have limitations with regards to emulation of all aspects of real fire evacuation scenarios, most notably missing cues that would be present in a real-world fire situation including smell (of smoke) and heat. Work being conducted at the \{redacted aims to address this by developing a multisensory system in which the visual representation of a fire scenarios is augmented with associated olfactory and thermal simulation. Figure 4 shows a prototype of this system, with patio heaters and a scent diffuser (visible in the background near the desk fan). As the user approaches the fire in the virtual environment, the fins in front of the patio heaters open, thereby increasing the level of heat the user experiences. Similarly, when the user's avatar is close to the virtual fire, the scent diffuser releases a smoke fragrance. 


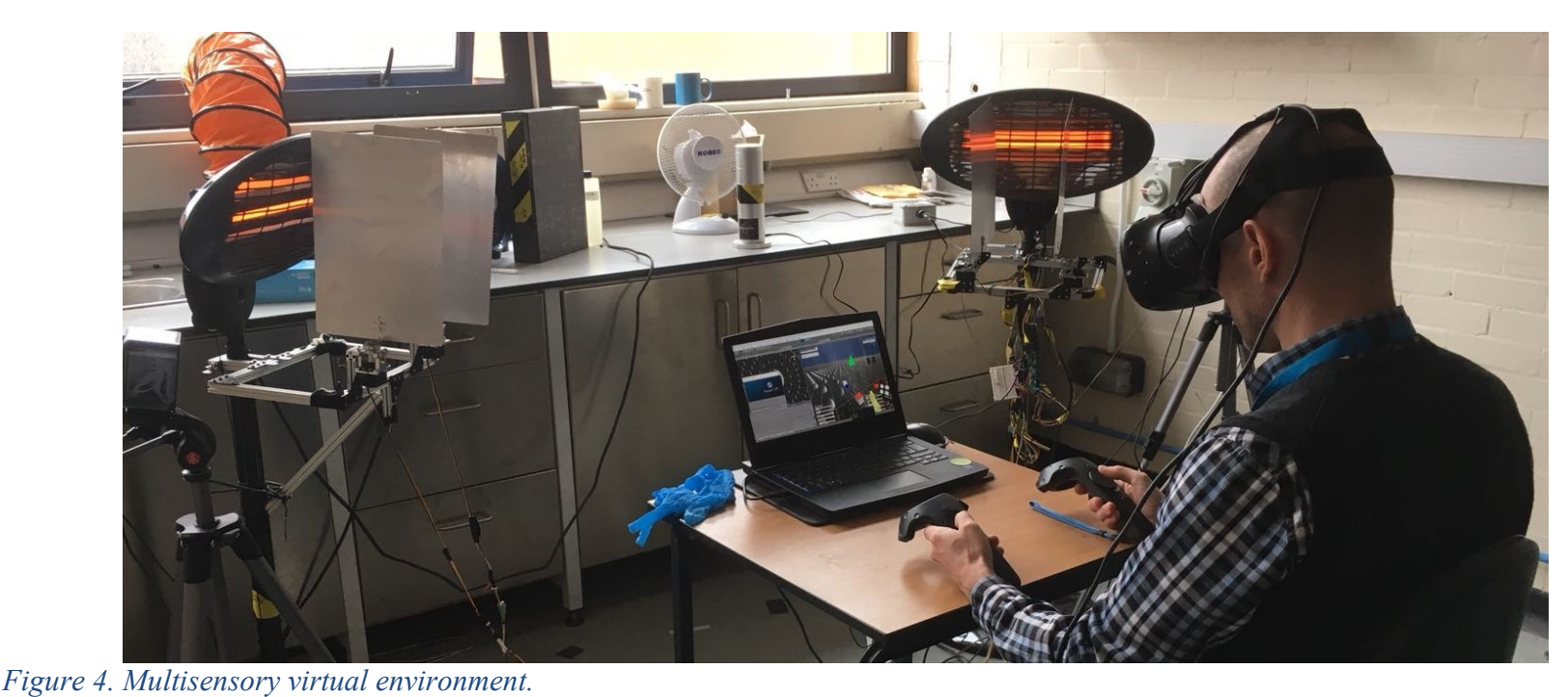

Figure 4. Multisensory virtual environment.

We expect that the use of multimodal sensory information will improve on behaviour and training issues associated with a lack of smell and heat simulation (Cha et al., 2012; Smith and Trenholme, 2009) and that increased realism of the training scenario will result in improved validity of trainee response behaviour (Chalmers and Ferko, 2008). Moreover, the greater fidelity of a multisensory simulator could increase the trainees' sense of presence within the scenario and therefore greater engagement with the training (Chertoff \& Schatz, 2015; Ketelhut, Clarke, \& Nelson, 2010).

Our training simulator is purposely developed using low cost technologies, to reduce the cost barrier to use of sophisticated, bespoke simulation systems which can be overly time-consuming to develop (Smith and Trenholme, 2009). We explored the potential of mobile, hand-held scanning technologies to reduce the burden of developing customised virtual environments. This method could enable a user to scan their own premises and then drag and drop pre-modelled salient interactive objects, such as fire call points and extinguishers into relevant places within the VE to create an engaging training scenario. We also provided increased fidelity of the training experience through the integration of additional sensory cues (i.e. heat and smell in addition to visual simulation of a fire) consistent with the user's proximity to the fire source. For technical details see Tahsiri, Lawson, Abdullah, \& Roper (2018) and Shaw et al (2019).

Development of a multimodal simulation system for fire safety training requires consideration of several design elements that will affect the user experience and, in consequence, the validity of user response to the simulation scenario. These include choice of computer hardware, graphics card, display type (e.g. head-mounted display, HMD, immersive system or non-immersive screen display), 3D navigation/interaction controller system, fragrance diffuser, heat generation source and dispersion system used. In combination, these influence the environmental richness and perceived realism and quality of the simulation and it is important that congruent information is presented to provide a coherent user experience (Hecht, Reiner, and Halevy, 2006). Positioning and proximity of the fragrance diffuser and heat source should allow for sufficient control of stimulus onset, intensity and cessation to match how these would be experienced in a real fire scenario. Extensive pilot testing was conducted to assess user perception of different types and strength of fragrances and location and intensity of the heat source. One issue, for example, is the disparity between the virtual fire and the actual heat source, as would occur if the user turns away from the virtual fire but the heat source remains in the same place. Wareing, Lawson, Abdullah, and 
Roper (2018)found that this disparity did not affect subjective realism, providing the heat sources were placed symmetrically, and sufficient heat (using at least two $2 \mathrm{KW}$ infrared heating devices) was used .

In addition to the selection, configuration and control of hardware elements of the system, we have had to make numerous decisions regarding design and implementation of software elements of the simulation. User navigation around the VE can be controlled via a combination of HMD viewpoint and hand-held movement controllers or, in non-immersive systems, hand-held controllers alone. Navigation and interaction will also be influenced by VE design features including layout, signage, instruction and information presentation, cues to support virtual object interaction and resulting interaction feedback response. One of the problems of using a simulation in which users are permitted to navigate freely, is that they may not fully explore the VE and therefore may not encounter the training activities as intended. We explored use of different methods to instruct users including directional arrows to show which route to follow and staged task instruction to ensure that they travelled to specific locations within the VE. Activation of fire simulation was triggered using collision boundaries and synchronised such that visual appearance, audio, olfactory and thermal cues were consistent with user proximity to the fire.

Future work will develop and test the multisensory simulator as a training tool, incorporating elements of gamification, such as progression through levels, awards, and challenge. It is important that this multisensory VET is evaluated against a range of criteria, including not only remembering key facts and procedures, but also attitudes towards health and safety and some measure of transference of training to the real world. We will compare the effectiveness of the multisensory VET system with traditional instruction-based methods of fire safety training.

\section{Conclusions}

Virtual environment training offers a range of advantages over other approaches, several of which are particularly relevant when training emergency response procedures. VET can provide experiential learning, which would be too dangerous in a real building fire. VEs can be engaging, particularly when using gamification, and provide the opportunity to record the training for evaluation and assessment. However, there are challenges with cybersickness and interaction with VEs, and the effectiveness of VET requires more empirical research.

A multimodal virtual environment, with simulated heat and smell, is being developed and tested at the \{redacted\} (Figure 4)We anticipate this will address concerns over the validity of fire evacuation behaviours demonstrated in unimodal VEs as multimodality increases user perception of being in a building fire, rather than a fire simulation (Shaw et al., 2019). Considering more broadly the future role of VE in firesafety training, key advantages of VEs are that they can be used in training programmes using few resources (time, costs, impact on company business) with high potential for re-use. In our system, this will be supported through the use of low-cost technologies in the VET. There is a general proliferation of commercially available low-cost VR devices which increase accessibility to this technology. Industrial collaborators in our research realised the possibilities of greater access to VR systems, such as allowing staff to complete part of their induction training off-site, thereby reducing the training time needed at the factory location. It is likely that this greater affordability will lead to greater use of VE in fire-safety and other forms of training, both audio-visual and multimodal systems. However, to be used appropriately, it is important that research is 
conducted into the benefits and drawbacks of such an approach, including a nuanced understanding of the training outcomes. A successful system will lead to improvements in current health and safety policy and practice through greater employee knowledge and understanding of OSH-related activities.

\section{Acknolwedgements}

\{redacted for review\}

\section{References}

Backlund, P., Engström, H., Gustavsson, M., Johannesson, M., Lebram, M., \& Sjörs, E. (2009). SIDH: a game-based architecture for a training simulator. International Journal of Computer Games Technology, 2009.

Backlund, P., Engstrom, H., Hammar, C., Johannesson, M. and Lebram, M. (2007), July. Sidh-a game based firefighter training simulation. In 2007 11th International Conference Information Visualization (IV'07) (pp. 899-907). Washington, DC: IEEE Computer Society.

Bandura, A. (2001). Social cognitive theory of mass communication. Media Psychology, 3, 265-299.

Borsci, S., Lawson, G. \& Broome, S. (2015). Empirical evidence, evaluation criteria and challenges for the effectiveness of virtual and mixed reality tools for training operators of car service maintenance. Computers in Industry, 67 (February 2015), 17-26.

Burnett, G. E., Irune, A., \& Mowforth, A. (2007). Driving simulator sickness and validity: how important is it to use real car cabins? [Special Issue]. Advances in transportation studies, 2007, 33-42.

Buttussi, F., \& Chittaro, L. (2018). Effects of different types of virtual reality display on presence and learning in a safety training scenario. IEEE transactions on visualization and computer graphics, 24(2), 1063-1076.

Cha, M., Han, S., Lee, J., \& Choi, B. (2012). A virtual reality based fire training simulator integrated with fire dynamics data. Fire Safety Journal, 50(May 2012), $12-24$.

Chalmers, A., \& Ferko, A. (2008). Levels of realism: From virtual reality to real virtuality. In Proceedings of the 24th Spring Conference on Computer Graphics (pp.19-25). New York, NY: ACM. 
Chertoff, D. B., \& Schatz, S. L. (2014). Beyond presence: how holistic experience drives training and education. In K. S. Hale \& K.M. Stanney (Eds.), Handbook of Virtual Environments: Design, Implementation, and Applications (pp. 857872). Boca Raton, FL: CRC Press, Taylor \& Francis Group.

Chittaro, L. \& Buttussi, F. (2015). Assessing knowledge retention of an immersive serious game vs. a traditional education method in aviation safety. IEEE transactions on visualization and computer graphics, 21(4), 529-538.

Chittaro, L. and Ranon, R., (2009). March. Serious Games for Training Occupants of a Building in Personal Fire Safety Skills. In 2009 Conference in Games and Virtual Worlds for Serious Applications (pp. 76-83). Los Alamitos, CA: IEEE Computer Society.

Crosier, J., Cobb, S., \& Wilson, J.R. (2002). Key Lessons for the Design and Integration of Virtual Environments in Secondary Science. Computers and Education, 38, $77-94$.

Dalgarno, B. and Lee, M.J.W. (2010). What are the learning affordances of 3-D virtual environments? British Journal of Educational Technology, 41(1), 10-32.

DiZio P, Lackner JR. (1997). Circumventing side effects of immersive virtual environments. In M. J. Smith, G. Salvendy, R. J. Koubek (Eds.), Advances in Human Factors/Ergonomics, (pp. 893-97). Amsterdam: Elsevier

Duarte, E., Rebelo, F., Teles, J., \& Wogalter, M. S. (2014). Behavioral compliance for dynamic versus static signs in an immersive virtual environment. Applied ergonomics, 45(5), 1367-1375.

Freeman, K. M., Thompson, S. F., Allely, E. B., Sobel, A. L., Stansfield, S. A., \& Pugh, W. M. (2001). A virtual reality patient simulation system for teaching emergency response skills to US Navy medical providers. Prehospital and Disaster medicine, 16(1), 3-8.

Gamberini, L., Cottone, P., Spagnolli, A., Varotto, D., \& Mantovani, G. (2003). Responding to a fire emergency in a virtual environment: different patterns of action for different situations. Ergonomics, 46(8), 842-858.

Gavish, N., Gutierrez Seco, T., Webel, S., Rodriguez, J., Peveri, M., \& Bockholt, U. (2011). Transfer of skills evaluation for assembly and maintenance training. In B. G. Bardy, J. Lagarde, \& D. Mottet (Eds.), Proceedings of the 2011 
International SKILLS Conference (Paper 28). Montpellier, France: EDP Sciences

Gavish, N., Gutiérrez, T., Webel, S., Rodríguez, J., Peveri, M., Bockholt, U. \& Tecchia, F. (2015). Evaluating virtual reality and augmented reality training for industrial maintenance and assembly tasks. Interactive Learning Environments, 23(6), 778-798.

Gonzalez-Franco, M., Pizarro, R., Cermeron, J., Li, K., Thorn, J., Hutabarat, W., \& Bermell-Garcia, P. (2017). Immersive mixed reality for manufacturing training. Frontiers in Robotics and AI, 4(3), 1.

Gwynne, S.M.V., Kuligowski, E.D., Boyce, K.E., Nilsson, D., Robbins, A.P., Lovreglio, R., Thomas, J.R. and Roy-Poirier, A. (2017, May). Enhancing egress drills: Preparation and assessment of evacuee performance. Fire and Materials.

Hecht, D., Reiner, M., and Halevy, G. (2006). Multimodal Virtual Environments: Response Times, Attention, and Presence. Presence, Teleoperators and Virtual Environments, 15(5), 515-23.

Home Office National Statistics (2018). Fire and rescue incident statistics: England, year ending March 2018. (Statistical Bulletin 16/18). Retrieved from Assets publishing website:

https://assets.publishing.service.gov.uk/government/uploads/system/uploads/attach ment_data/file/732555/fire-and-rescue-incident-march-2018-hosb1618.pdf

Jennings, S., Reid, L. D., Craig, G., \& Kruk, R. V. (2004). Time delays in visually coupled systems during flight test and simulation. Journal of Aircraft, 41(6), 1327-1335.

Jensen, L., \& Konradsen, F. (2018). A review of the use of virtual reality head-mounted displays in education and training. Education and Information Technologies, 23(4), 1515-1529.

Jiang, L., Girotra, R., Cutkosky, M. R., \& Ullrich, C. (2005, March). Reducing error rates with low-cost haptic feedback in virtual reality-based training applications. In First Joint Eurohaptics Conference and Symposium on Haptic Interfaces for Virtual Environment and Teleoperator Systems. World Haptics Conference (pp. 420-425). IEEE.

Kalawsky, R. S. (1996). Exploiting Virtual Reality Techniques in Education and Training: Technological Issues. SIMA Report Series, 26(1), 1356-5370. 
Kassem, M., Benomran, L., \& Teizer, J. (2017). Virtual environments for safety learning in construction and engineering: seeking evidence and identifying gaps for future research. Visualization in Engineering, 5(1), 16.

Ketelhut, D. J., Clarke, J., \& Nelson, B. C. (2010). The development of River City, a multi-user virtual environment-based scientific inquiry curriculum: historical and design evolutions. In Designs for learning environments of the future (pp. 89-110). Springer, Boston, MA.

Kinateder, M., Ronchi, E., Nilsson, D., Kobes, M., Müller, M., Pauli, P., \& Mühlberger, A. (2014, September). Virtual reality for fire evacuation research. In 2014 Federated Conference on Computer Science and Information Systems (pp. 313321). IEEE.

Kobes, M., Helsloot, I., de Vries, B., \& Post, J. G. (2010a). Building safety and human behaviour in fire: A literature review. Fire Safety Journal, 45(1), 1-11.

Kobes, M., Helsloot, I., de Vries, B., \& Post, J. G. (2010b). Exit choice,(pre-) movement time and (pre-) evacuation behaviour in hotel fire evacuationBehavioural analysis and validation of the use of serious gaming in experimental research. Procedia Engineering, 3, 37-51.

Langley, A., Lawson, G., Hermawati, S., D'Cruz, M., Apold, J., Arlt, F., \& Mura, K. (2016). Establishing the usability of a virtual training system for assembly operations within the automotive industry. Human Factors and Ergonomics in Manufacturing \& Service Industries, 26(6), 667-679.

Laurillard, D. (2010). Rethinking University Teaching: a framework for the effective use of learning technologies. TechTrends, 69.

Lawson, G. (2011). Predicting human behaviour in emergencies (Doctoral dissertation, University of Nottingham)

Leder, J., Horlitz, T., Puschmann, P., Wittstock, V., \& Schütz, A. (2019). Comparing immersive virtual reality and powerpoint as methods for delivering safety training: Impacts on risk perception, learning, and decision making. Safety science, 111, 271-286.

Luo, L., Yin, H., Cai, W., Lees, M., \& Zhou, S. (2013). Interactive scenario generation for mission-based virtual training. Computer Animation and Virtual Worlds, 24(3-4), 345-354. 
Mantovani, F., \& Castelnuovo, G. (2003). Sense of presence in virtual training: enhancing skills acquisition and transfer of knowledge through learning experience in virtual environments. In G. Riva, F. Davide, \& W. A. IJsselsteijn (Eds.), Being there: Concepts, effects and measurement of user presence in synthetic environments (pp. 167-181). Amsterdam, The Netherlands: Ios Press.

Mantovani, F., Castelnuovo, G., Gaggioli, A., \& Riva, G. (2003). Virtual reality training for health-care professionals. CyberPsychology \& Behavior, 6(4), 389-395.

MarketWatch. (2018). Global Fire Safety Systems and Equipment Market (2017-2023): Forecast By Types, Verticals, Regions and Competitive Landscape - Research and Markets. [online] MarketWatch. Available at: http://www.marketwatch.com/press-release/global-fire-safety-systems-andequipment-market-2017-2023-forecast-by-types-verticals-regions-and-competitivelandscape---research-and-markets-2017-12-01 (Accessed 9 Sep. 2018).

McGuire, E. G. (1996). Knowledge representation and construction in hypermedia environments. Telematics and Informatics, 13(4), 251-260.

McMahan, R. P., Schafrik, S., Bowman, D. A., Karmis, M. (2010). Virtual environments for surface mining powered haulage training. In: J. Brune (Ed.). Extracting the science: a century of mining research. SME, pp. 520-528.

Nichols, S. (2000). Individual characteristics and experiences of virtual reality induced symptoms and effects (VRISE). In Proceedings of the Human Factors and Ergonomics Society Annual Meeting (Vol. 44, No. 5, pp. 538-541). Sage CA: Los Angeles, CA: SAGE Publications.

Nichols, S., Cobb, S., \& Wilson, J. R. (1997). Health and safety implications of virtual environments: Measurement issues. Presence: Teleoperators \& Virtual Environments, 6(6), 667-675.

Nickel, P., Pröger, E., Lungfiel, A., \& Kergel, R. (2015, March). Flexible, dynamic VR simulation of a future river lock facilitates prevention through design in occupational safety and health. In 2015 IEEE Virtual Reality (VR) (pp. 385386). IEEE.

Nilsson, T., Roper, T., Shaw, E., Lawson, G., Cobb, S. V., Meng-Ko, H., \& Khan, J. (2019, April). Multisensory Virtual Environment for Fire Evacuation Training. In Extended Abstracts of the 2019 CHI Conference on Human Factors in Computing Systems (p. INT044). ACM. 
Perez, B. Z., Marin, M. M., \& Perez, E. I. (2007, September). Developing a virtual environment for safety training. In Electronics, Robotics and Automotive Mechanics Conference (CERMA 2007) (pp. 545-550). IEEE.

Pfandler, M., Lazarovici, M., Stefan, P., Wucherer, P., \& Weigl, M. (2017). Virtual reality-based simulators for spine surgery: a systematic review. The Spine Journal, 17(9), 1352-1363.

Ragan, E. D., Bowman, D. A., Kopper, R., Stinson, C., Scerbo, S., \& McMahan, R. P. (2015). Effects of field of view and visual complexity on virtual reality training effectiveness for a visual scanning task. IEEE transactions on visualization and computer graphics, 21(7), 794-807.

Rebelo, F., Noriega, P., Duarte, E., \& Soares, M. (2012). Using virtual reality to assess user experience. Human Factors, 54(6), 964-982.

Ren, A., Chen, C., \& Luo, Y. (2008). Simulation of emergency evacuation in virtual reality. Tsinghua Science and Technology, 13(5), 674-680.

Ren, A., Chen, C., Shi, J., \& Zou, L. (2006). Application Of Virtual Reality Technology To Evacuation Simulation In Fire Disaster. In H. R. Arabnia (Ed), Proceedings of the 2006 International Conference on Computer Graphics and Virtual Reality (pp. 15-21). USA: CSREA Press.

Renner, R. S., Velichkovsky, B. M., \& Helmert, J. R. (2013). The perception of egocentric distances in virtual environments-a review. ACM Computing Surveys (CSUR), 46(2), 1-40.

Ribeiro, J., Almeida, J. E., Rossetti, R. J., Coelho, A., \& Coelho, A. L. (2012, June). Using serious games to train evacuation behaviour. In 7th Iberian Conference on Information Systems and Technologies (CISTI 2012) (pp. 1-6). IEEE.

Riva, G., Wiederhold, B. K., \& Gaggioli, A. (2016). Being different: The transformative potential of virtual reality. Annual Review of CyberTherapy and Telemedicine, 14, 3-6.

Sharples, S., Burnett, G. and Cobb, S. (2011). Sickness in Virtual Reality. In S. Bouchard and B. Wiederhold (Eds). Treatment of Anxiety Disorders with Virtual Reality, Springer Publications.

Sharples, S., Cobb, S., Moody, A., \& Wilson, J. R. (2008). Virtual reality induced symptoms and effects (VRISE): Comparison of head mounted display (HMD), desktop and projection display systems. Displays, 29(2), 58-69. 
Shaw, E., Roper, T., Nilsson, T., Lawson, G., Cobb, S. V. G. Miller, D. (2019, May). The heat is on: exploring user behaviour in a multisensory virtual environment for fire evacuation. In CHI '19 Proceedings of the 2019 CHI Conference on Human Factors in Computing Systems (Paper No. 626). New York, NY: ACM.

Smith, J., \& Veitch, B. (2019). A better way to train personnel to be safe in emergencies. ASCE-ASME Journal of Risk and Uncertainty in Engineering Systems, Part B: Mechanical Engineering, 5(1), 011003.

Smith, S. P., \& Trenholme, D. (2009). Rapid prototyping a virtual fire drill environment using computer game technology. Fire safety journal, 44(4), 559-569.

Smith, S., \& Ericson, E. (2009). Using immersive game-based virtual reality to teach fire-safety skills to children. Virtual reality, 13(2), 87-99.

Taffinder, N. J., McManus, I. C., Gul, Y., Russell, R. C. G., \& Darzi, A. (1998). Effect of sleep deprivation on surgeons' dexterity on laparoscopy simulator. The lancet, 352(9135), 1191.

Tahsiri, M., Lawson, G., Abdullah, C., \& Roper, T. (2018, March). A multisensory virtual environment for OSH training. In 2018 IEEE Conference on Virtual Reality and 3D User Interfaces (VR) (pp. 699-700). IEEE.

Tang, C. H., Wu, W. T., \& Lin, C. Y. (2009). Using virtual reality to determine how emergency signs facilitate way-finding. Applied ergonomics, 40(4), 722-730.

Tate, D. L., Sibert, L., \& King, T. (1997). Virtual environments for shipboard firefighting training. In Virtual reality annual international symposium, 1997., IEEE 1997 (pp. 61-68). IEEE.

Travis, D., Watson, T., \& Atyeo, M. (1994). Human psychology in virtual environments. Interacting with virtual environments (1994), 43-59.

Wann, J.P., Rushton, S., \& Mon-Williams, M. (1995). Natural Problems for Stereoscopic Depth Perception in Virtual Environments. Vision Research, 35(19), 2731-2736.

Wareing, J., Lawson, G., Abdullah, C., and Roper, T. (2018). User Perception of Heat Source Location for a Multisensory Fire Training Simulation. In: Proceedings of the Computer Science and Electronic Engineering Conference, CEEC 2018, Essex, UK. 
Webber-Youngman, R. C. W., \& Van Wyk, E. A. (2013). Incident reconstruction simulations-potential impact on the prevention of future mine incidents. Journal of the Southern African Institute of Mining and Metallurgy, 113(6), 519-528.

Webel, S., Bockholt, U., Engelke, T., Gavish, N., Olbrich, M., \& Preusche, C. (2013). An augmented reality training platform for assembly and maintenance skills. Robotics and Autonomous Systems, 61(4), 398-403.

Winn, W. (1993). A conceptual basis for educational applications of virtual reality. (HITL Technical Report no. R-93-9). University of Washington, Seattle: Human Interface Technology Laboratory.

Witmer, B. G., Bailey, J. H., Knerr, B. W., \& Parsons, K. C. (1996). Virtual spaces and real world places: transfer of route knowledge. International journal of humancomputer studies, 45(4), 413-428.

Wood, P.G. (1980). A survey of behaviour in fires. In: D. Canter (Ed.) Fires and Human Behaviour. New York: John Wiley and Sons, pp.83-96.

Youn, E. (2007). The effectiveness of a virtual learning environment on student learning about clinical skills (Doctoral dissertation). Available from uta.edu. Texas, The University of Texas at Arlington.

Youngblood, P. L., Srivastava, S., Curet, M., Heinrichs, W. L., Dev, P., \& Wren, S. M. (2005). Comparison of training on two laparoscopic simulators and assessment of skills transfer to surgical performance. Journal of the American College of Surgeons, 200(4), 546-551. 